\title{
Kendinden açılandırılabilir lag screw (kilitleme vida)'ı proksimal femur çivisi (PFN)
}

\author{
Proximal femoral nail (PFN) with self-angling locking screw
}

\author{
Reşit Sevimli
}

SBÜ Kanuni Eğitim Araştırma Hastanesi, Ortopedi ve Travmatoloji Kliniği, İstanbul

\begin{abstract}
Mevcut buluş, tıp alanında, ortopedi ve travmatoloji dalında erişkin ve yaşlılarda görülen femur (uyluk kemiği) üst uç kırıkları (intertrokanterik kırı) için kullanılan çivilerde proksimaldeki tek delikten femur başına aynı çivi üzerinde değişik açılarda vida (lag screw) gönderilmesine olanak sağlayan intramedüller (kanal içi) çivi yapılanması ile ilgilidir. Ayrıca mevcut buluş femurun (uyluk kemiğinin) üst ucunun (trokanterik bölge) kanal içi şekline uyum sağlayacak şekilde bu bölgenin anatomisine uygun şekilde eğim verilmiş sağ ve sol femur üst uçları için ayrı ayrı olmak üzere farklı çap fakat aynı boylarda olabilen femur boynu anteversiyonuna uyumlu tek çivi üzerinden farklı açılarda tek sabitleme bıçağına müsaade edebilen ve sabitleme elemanı deliklerinden oluşan kanal içi çivi uygulaması ile yeterli stabilite elde edildiği gösterilmiştir.
\end{abstract}

Anahtar sözcükler: proksimal femur; kilitleme vidası; femur çivisi; açılandırma

\section{T. C. Türk Patent Enstitüsü'ne Faydalı Model Belgesi için Başvuru Bilgileri[ ${ }^{1]}$}

Başvuru bilgileri Tablo 1'de gösterilmiştir. ${ }^{[1]}$

Tablo 1. Başvuru bilgileri ${ }^{[1]}$

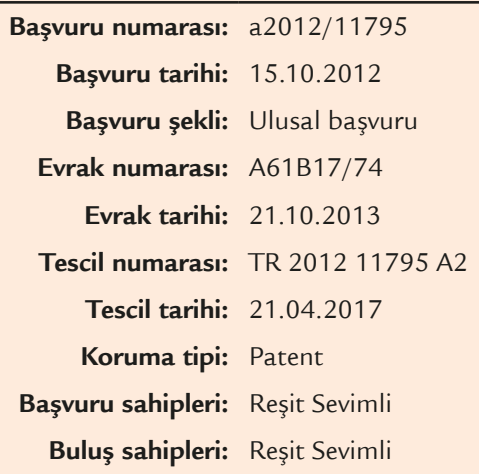

Başvuru numarası: a2012/11795

Başvuru tarihi: 15.10 .2012

Başvuru şekli: Ulusal başvuru

Evrak numarası: A61B17/74

Evrak tarihi: 21.10 .2013

Tescil numarası: TR 201211795 A2

Tescil tarihi: 21.04.2017

Koruma tipi: Patent

Başvuru sahipleri: Reşit Sevimli

Buluş sahipleri: Reşit Sevimli

This invention in the field of orthopaedics and traumatology of medicine aims to provide lag screw applications with variable angles from the proximal hole of the femoral nails on elderly adult patients with femoral proximal fractures. Also; the present invention conforms to the intra-canal shape of the upper end of the femur (thigh bone) (trochanteric region) on the right, and the femoral neck, which can be different in diameter but of the same length, for the right and left upper ends of the femur that are inclined by this anatomy. It has been shown to obtain sufficient stability with the application of the nail inside the canal consisting of the fixing element holes and allowing a single fixing blade at different angles over a single nail compatible with the anteversion.

Key words: proximal femoral; locking screw; femoral nail; angulation

\section{PATENT BELGESi - No: TR 201211795 B ${ }^{[1]}$}

\section{Teknik Alan ${ }^{[1]}$}

"Mevcut buluş, tıp alanında, ortopedi ve travmatoloji dalında erişkin ve yaşlılarda görülen femur (uyluk kemiği) üst uç kırıkları (intertrokanterik kırık) için kullanılan çivilerde proksimaldeki tek delikten femur başına aynı çivi üzerinde değişik açılarda vida (lag screw) gönderilmesine olanak sağlayan intramedüller (kanal içi) çivi yapılanması ile ilgilidir."

\section{Önceki Teknik/Teknikler ${ }^{[1]}$}

"Kırık dış etkiler, trafik kazaları, düşme gibi nedenlerle oluşan kemikte ayrılmaya neden olan anatomik bütünlük kaybıdır. Kemikteki kırılma kuvvetin şiddetine göre hafif bir çatlaktan tamamen ayrılmalara kadar varabilen çıkıklarında etki edebildiği ağrılı bir durumdur. ${ }^{[1]}$

- Illetişim adresi: Doç. Dr. Reşit Sevimli, SBÜ Kanuni Eğitim Araştırma Hastanesi, Ortopedi ve Travmatoloji Kliniği, İstanbul Tel: 0534 - 5738724 e-posta: resitsevimli@hotmail.com ORCID iD: 0000-0002-5394-9100

- Geliștarihi: 16 Kasım $2020 \quad$ Kabul tarihi: 26 Kasım 2020 
Femur (uyluk kemiği) kemiği insan vücudundaki en uzun ve en kuvvetli kemiktir. Bu kemik kırıkları için kullanılan proksimal femoral çiviler (PFN) günümüzde farklı firma ve modellerle kullanımdadır. Hepsi femur (uyluk kemiği) intertrokanterik bölge kırıkları için tasarlanmış olup, benzer yapıda hepsinde femoral çivi komponenti, başa gönderilen vida, distale gönderilen vida ve tepe vidasından (end cup) oluşmaktadır. Bahsedilen sistemler içerisinde diğer uzun kemik kırıklarında olduğu gibi torakanterik bölge kırıkları için kullanılmaya başlanan kanal içi çiviler diğer yöntemler kadar sık kullanılmaya başlanmıştır. ${ }^{[2]}$

Kırığın tipine göre kilitli ve kilitsiz çivileme teknikleri kullanılmaktadır. Kilitli çivileme özellikle parçalı kırıklarda tercih edilmektedir. Kanal içi uygulanan intramedüller çivileme tekniklerinde ameliyat süresinin kısa sürmesi, az kan kaybının yanı sıra hastanın erken hareket etmesine müsaade etmesi de diğer avantajlarındandır. ${ }^{[3]}$

Literatürde konu ile ilgili yer alan patentlerden biri olan EP08... (A1) numaralı Avrupa patent başvurusunda, femurdaki proksimal kırıklar için kemik iliği boşluğuna takılmak üzere geliştirilen çivi sisteminde proksimal (yukarı) bölge üzerinde kırı̆̆ı sabitlemeye müsaade edecek vidanın takılabilmesinin yanında distalde (aşağı) yine vida giriş deliği olan sistemdir.

Yine Avrupa patent başvurusu olan EP16... (B1) numaralı çivi sistemi trokantere uzanan pertrokanterik kırıkları ve femur boyun kırıkları tabanındaki kırıklar için geliştirilmiş benzer endomedüller bir çivi sistemidir. ${ }^{[4,5]}$ TR19... numaralı femur tibia kırıkları için geliştirilen ulusal faydalı model başvurusu da tibia ve femur orta kırıkları için geliştirilmiş üst ve alt kısımlarında sabitleme için kilitleme delikleri olan diğer çivi tasarımlarıdır. ${ }^{[6,7]}$ ”

\section{Buluşun Kısa Tarifi ${ }^{[1]}$}

"Mevcut buluş yukarıda bahsedilen dezavantajları ortadan kaldırmak ve ilave bazı avantajları sağlamak için tasarlanmış, trokanterik çivilerle ilgilidir ${ }^{[1]}$;

- Buluşun bir amacı anteversiyon kusuru nedeni ile femur başına giden sabitleme elemanını (lag vidası) her açıdan merkezlenmesine müsaade edip diğer çivi sistemlerinden çok daha hızlı ve etkin olarak sağlanabilmesidir. Bahsedilen anteversiyon açısının kırık redüksiyonunu bozan ek açı düzeltme işlemlerine gerek kalmamasını sağlamaktir. ${ }^{[1]}$

- Buluşumuz diğer bir amacı yukarıda belirttiğimiz PFN çivilerinde proksimal kilitlemeye farklı bir yaklaşım getirmekte olup diğer çivilerde her farklı açı için farklı çivi kullanılması gerekirken, buluşumuzda tek çivi üzerinden farklı açılarda başa vida (lag screw) gönderilmesine olanak sağlayan kullanışlı bir sistemdir. ${ }^{[1]}$
- Buluşun diğer bir amacı küçük bir kesi ile en az kanama ve hastaya en az ameliyat yükü getirecek şekilde yerleştirilmesine müsaade eden proksimalde tek vida ve distalde tek vida ile sabitleme sağlayan sistem oluşudur. ${ }^{[1]}$

Yukarıdaki bahsedilen amaçları gerçekleştirmek üzere buluş birbiri ile bütünleşik proksimal ve distal parçaya sahip, bahsedilen proksimal parça üzerinde tek bir sabitleme elemanı ve yuvada bir adet bilye aparatının yanında distalde tek bir vida ile sabitlemeye müsaade eden, kemik iliği kanalında yumuşak dokuya zarar vermeden uygulama yapılmasına müsaade eden femur boynuna uyumlu (anatomik) femur torakanterik ve boyun kırıklarında kullanıma müsaade eden intramedüller olarak (kanal içi) kullanılan bir trokanterik çividir. ${ }^{[1]}$ ”

\section{Buluşun Detaylı Açıklanması ${ }^{[1]}$}

"Kendinden açılandırılabilir lag screw (kilitleme vida)'li PFN çivisi sistemimizde amaç 120, 125, 130, 135 derece ile yerleştirilen çivileri tek bir çivide birleştirilip intra-op (ameliyat esnasında) çivi değişimine gerek duyulmadan femur intertrokanterik ve boyun kırıklı hastalarda lag screw (kilitleme vidası)'nin uygun açıla yerleştirilmesidir. ${ }^{[1]}$

Sistemde lag (proksimal kilitleme) vidasının açılandırılabilmesi için çivinin boyun bölgesinde tüm planlarda açıIanmaya izin veren bilye aparatı ile bunu sağlayacă̆ımızı düşünüyoruz. ${ }^{[1]}$ ”

Sistem şu parçalardan oluşmaktadır:

- Açılandırmaya müsade eden bilyeli proksimal femur çivisi[ ${ }^{[1]}$

1- Bilye aparatı

2- Lag screw (kilitleme vidası)

3- Tek distal kilitleme vidası

4- End cup (tepe vidası)

5- Small end cup (iç kilitleme vidası)

Sistemde bilye aparatı 120 ile135 derece arasında süperior (yukarı) ve inferior (aşağı) planda, 0-20 derece arasında anterior-posterior (ön) planda hareket etmeye izin vermelidir (Şekil 1).

Harekete izin veren bilye aparatında lag (kilitleme) vidası için giriş deliklerinin yanında gayd (klavuz) için giriş çıkış deliklerinin olması gerekmektedir (Şekil 2).

Bilye aparatının çivi içinde sabitlenmesi için mini end cup ile sabitlemek gerekmektedir. Tüm sistem yerleştirildikten sonra distal kilitleme ve end cup yerleştirilip işleme son verilir (Şekil 3). 


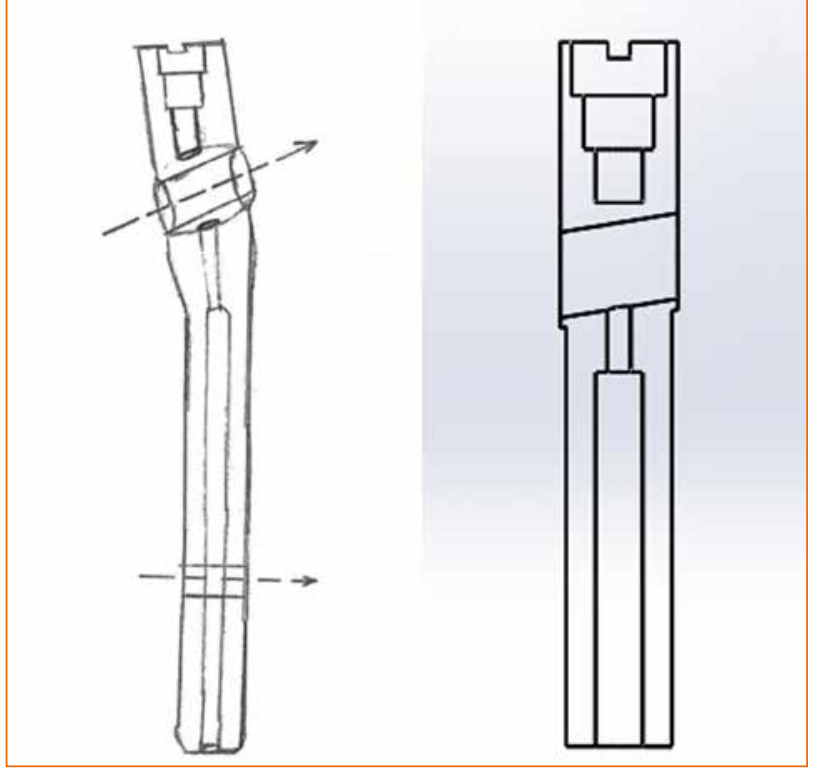

Şekil 1. Buluşun tercih edilen bir şekline uygun olarak geliştirilen ve kemiğe intramedüller (kemik iliği) takılan bahsedilen trokanterik çivinin iki boyutlu yandan görünümü verilmektedir. ${ }^{[1]}$

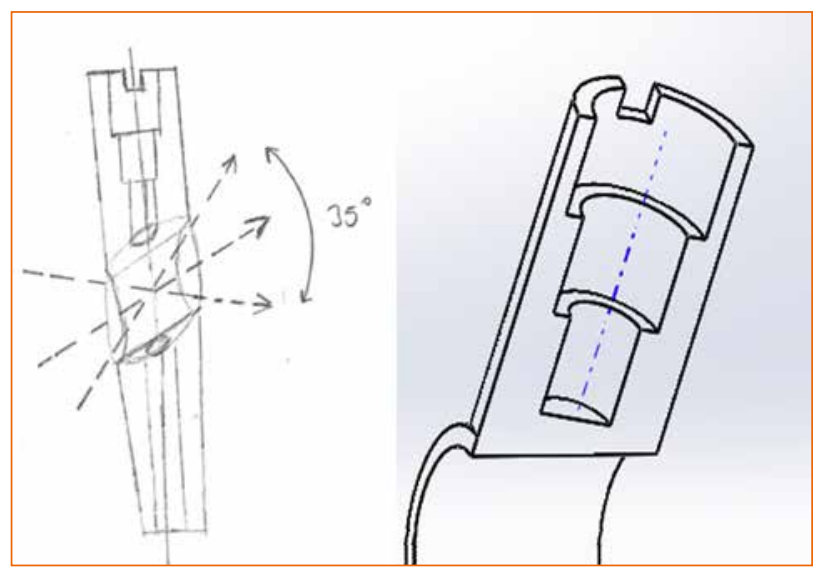

Şekil 2. Buluş konusu trokanterik çivinin proksimal parçasında bulunan tek sabitleme elemanı yuvası ve bu yuvadan geçen sabitleme elemanının farklı açılarda gösterildiği kesit görünümleri.[1]

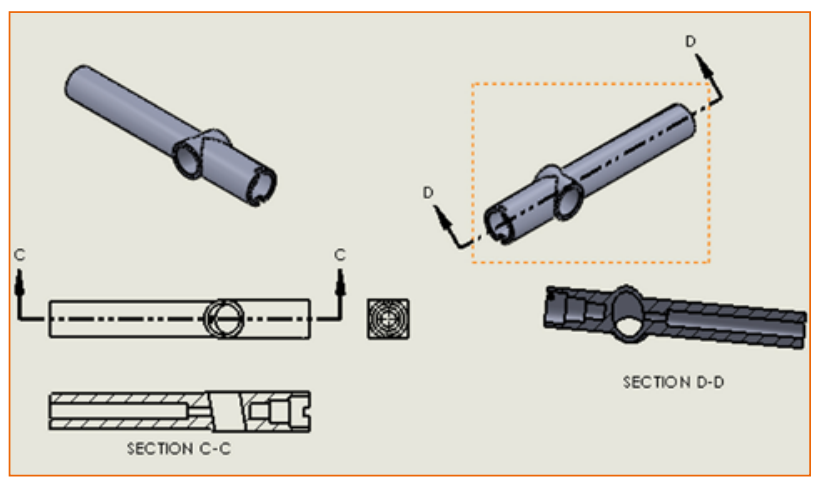

Şekil 3. Buluş konusu trokanterik çivinin femur kemiğine intramedüller olarak takıldığı durumda, distal parçasına distal tek sabitleme elemanı ile kilitlendiği yan perspektif görünümler. ${ }^{[1]}$
Çizimlerin mutlak ölçeklendirmemesi gerekmemektedir ve mevcut buluşu anlamak için gerekli olmayan detaylar ihmal edilmiş olabilmektedir. Ayrıca en azından büyük ölçüde özdeş olan veya en azından büyük ölçüde özdeşleri olan elemanlar aynı numara ile gösterilmektedir.”

\section{İstemler ${ }^{[1]}$}

"1- Buluş, femur kemiğinin üst ucunun kanal içi yapısına uyum sağlayacak şekilde bu bölgenin anatomik yapısı göz önüne alınarak eğimli olarak oluşturulan, sağ ve sol femur üst uçlan için ayrı ayrı olmak üzere farklı çap ve boylarda olabilen, femur boynu anteversiyonu ile uyumlu olacak şekilde boyun ve başa açılandırma aparatıyla değiş̧ik açılarda giden bir sabitleme vidası, bu aparatı kilitleyen küçük end cup ve tepeyi kilitleyen tepe end cup yanı sıra alt uçta vücudun uzunlamasına olan eksenine dik açı istikametinde tek sabitleme elemanı (distal kilitleme vidası) göndermeye uygun sabitleme elemanı yuvasından oluşan kanal için uygulamalı bir trokanterik çivi olup özelliği; başa açılandırma aparatıyla değişik açılarda giden bir sabitleme vidası içermesi ile karakterizedir. ${ }^{[1]}$

2- Buluş istem 1'de bahsedilen çivi olup, özelliği; anteversiyon kusuru nedeni ile femur başına giden her açıdan merkezlenmesine müsaade eden sabitleme vidası (lag vidası) içermesi ile karakterizedir.

3- Buluş istem 1-2'de belirtilen çivi olup, özelliği; bahsedilen anteversiyon açısının kırık redüksiyonunu bozan ek açı düzeltme işlemlerine gerek kalmamasının sağlayan açılandırma aparatı içermesi ile karakterizedir.

4- Buluş PFN çivilerinde proksimal kilitlemeye farklı bir yaklaşım getirmekte olup diğer çivilerde her farklı açı için farklı çivi kullanılması gerekirken, buluşumuzda tek çivi üzerinden farklı açılarda başa vida (lag screw) gönderilmesine olanak sağlayan açılandırma aparatı içermesi ile karakterizedir.

5- Buluş, küçük bir kesi ile en az kanama ve hastaya en az ameliyat yükü getirecek şekilde yerleştirilmesine müsaade eden proksimalde tek vida ve distalde tek vida ile sabitlemesini sağlayan sistem olması ile karakterizedir.

6- İstem 1-5'e uygun olarak hazırlanan proksimal femur çivisi olup özelliği, başa gönderilen tek kilitleme vidası ve bu kilitleme vidasının değişik yönlere açılandırılmasına müsaade eden açılandırma aparatı (bilye) içermesidir. ${ }^{[1]}$

7- Istem 1-6'ya uygun trokanterik çivi olup özelliği, kilitleme aparatını kilitleyecek küçük tepe vidası (small end cup) ve çivi tepesini kapatacak büyük tepe vidası içermesi ile karakterizedir.

8- İstem 1-7'ye uygun trokanterik çivi olup özelliği, bilye aparatı yukarı aşağı ve iç dış yönde belirli açılarda hareket edebilmeye müsaade edilecek şekilde olmasıdır. 
9- Istem 1-8'e uygun trokanterik çivi olup özelliği, bilye aparatında klavuz geçişine izin verecek şekilde kanallı yapıda olması ile karakterizedir.

10- İstem 1-9'a uygun olarak trokanterik çivi olup özelliği, distal kilitleme için tek vida kullanılmasına gerek duyulmasıdır. ${ }^{[1] "}$

\section{KAYNAKLAR}

1. Kendinden Açılandırılabilir Lag Screw (Kilitleme Vida)'lı Proksimal Femur Çivisi (Pfn). T. C. Türk Patent Enstitüsü. Patent belgesi. No: 2012/11795. https://portal.turkpatent. gov.tr/anonim/arastirma/patent/detayli

2. Asnis SE, Wanek-Sgaglione L. Intracapsular Fractures of the Femoral Neck. J Bone Joint Surg 1994;76:1793-803. Crossref
3. Bray TJ. Femoral neck fracture fixation. Clinical decision making. Clin Orthop Relat Res 1997;339:20-31. Crossref

4. Swiontkowski MF. Current Concepts Review: Intracapsular Fractures of the Hip. J Bone Joint Surg 1994;76:129-38. Crossref

5. Jakob M, Rosso R, Weller K, Babst R, Regazzoni P. Avascular necrosis of the femoral head after open reduction and internal fixation of femoral neck fractures: an inevitable complication? Swiss Surg 1999;5:257-64. Crossref

6. Rajan DT, Parker MJ. Does the level of an intracapsular femoral fracture influence fracture healing after internal fixation? A study of 411 patients. Injury 2001;32:53-6. Crossref

7. Rodríguez-Merchán EC. In situ fixation of nondisplaced intracapsular fractures of the proximal femur. Clin Orthop Relat Res 2002;399:42-51. Crossref 